\title{
Complementary and alternative medicine
}

\author{
An overview of nontraditional medicine on the Web
}

by Julia K. Nims

$I^{2}$ n 2002, Americans are expected to spend $\$ 50$ billion dollars on complementary and alternative medicine (CAM).' Already four out of ten U.S. adults claim to have used some type of nonconventional treatment for an illness or condition. ${ }^{2}$ With the surge of interest in nontraditional medicine, it isn't surprising that there are thousands of Web sites devoted to different CAM therapies, such as alternative health systems (homeopathic medicine and traditional Chinese medicine), mind-body medicine, herbal medicine and nutrition therapies, body-based therapies, and energy therapies. ${ }^{3}$

Although often grouped together, complementary and alternative therapies are different. Complementary therapies are used in conjunction with traditional Western medicine, while alternative therapies are used in place of traditional medicine. The majority of the sources listed below explore both complementary and alternative medicine and are considered CAM sites.

Selection for this list was based on reliability of the site's publisher or sponsor, the purpose of the site, the extent and origin of content on the site, its currency, and its accessibility to the health care consumer. Web sites without disclaimers, editorial policies, or explicit authorship were excluded. Sites with advertising or a shopping feature appear only if their content and reliability outweigh the commercial elements.

\section{Metasites}

- Alternative Medicine: Health Care Information Resources. McMaster University's Health Sciences Library is responsible for this massive collection of CAM links. Decidedly international in scope, this site offers lengthy descriptions of a vast array of alternative healthrelated Web sites. The first section directs visitors to sources about complementary and alternative medicine in general. Subsequent sections are listed by therapy and provide access to more specific resources. Access: http://wwwhsl.mcmaster.ca./tomflem/altmed.html.

- The Alternative Medicine Homepage. Charles B. Wessel, a medical librarian at the University of Pittsburgh's Faulk Library of Health Sciences, created this comprehensive site more than seven years ago. The site's homepage has a brief, but thorough description of what CAM is and how it is defined. The site has eight major topic areas: AIDS and HIV, Databases, Internet Resources, Mailing Lists and Newsgroups, Government Resources, Pennsyl-

\footnotetext{
Alternative Databases [ Internet Resources | Mailing Lists \& Newsgroups Medicine AIDS \& HIV| Practitioner's Directories | Related Resources

HomePage Government Resources| Pennsylvania Resources
}

\section{About the author}


vania Resources, Practitioners' Directories, and Related Resources. Each item in a topic area has a brief description. Access: http:// www. pitt.edu/ cbw/altm.html.

- Ask NOAH About: Complementary and Alternative Medicine. NOAH ( $\mathrm{New}$ York Online Access to Health) is a collaboration among several libraries in New York City, including the New York Public Library and the City University of New York (CUNY) Office of Library Services. This extensive site lists several alternative therapies, such as "Apitherapy," "Homeopathy," and "Qi-Gong." Under each therapy, users can select a subtopic under "The Basics" or "Resources." The choices under "The Basics" lead users to descriptive and explanatory information from other sites, including government sites, associations, and online magazines. The "Resources" portion of each subtopic usually leads to associations, databases, and directories. Access: http://www.noahhealth.org/english/alternative/alternative.html.

\section{Complementary and alternative medicine sites}

- DrWeil.com. Andrew Weil is a physician, the author of several books and articles, and the founder of the Program in Integrative Medicine at the University of Arizona Health Sciences Center in Tucson. His Web site offers information on health conditions and therapies, home health remedies, and nutrition and vitamin tips. The site also features chats with Weil, community message boards, and an electronic newsletter. There are advertisements and a shopping section on the Web site. Access: http:///www.drweil.com.

- HealthWorld Online. HealthWorld Online believes individuals should be major players in their own health care, and that integrative medicine-the blending of the best of alternative and conventional medicine-can help achieve wellness and health. Unlike most

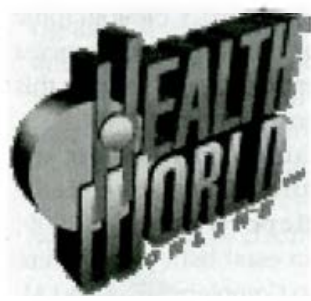
other CAM sites, Health World Online lists conventional and alternative therapies for common health conditions side by side for easy comparison. Much of the content for the site comes from book excerpts, articles, and other Web sites. Additional resources include provider directories, expert columns, and news centers. The site does accept some advertising. Access: http://www. healthy.net.

- HerbMed. A project of the Alternative Medicine Foundation (see description below), this database of herbs and their uses allows users to browse by scientific or common name. Information about each herb may contain its efficacy, how it is prepared, herb activity, and warnings or contraindications. The majority of the information comes from PubMed and other research sites available on the Web. Access: http://www.herbmed.org.

- Internet Health Library. This site claims to be the United Kingdom's largest alternative medicine, complementary therapy, and natural health care resource. Visitors can learn about the different therapies, how they work, their use in treatments, and how they can help a variety of ailments and conditions. Searching by health problem leads to information about causes, symptoms, diagnosis, additional information, and conventional treatments. This site also features a "Homeopathic Library," health news, and links to organizations. There is some advertising on the site. Access: http:// wow. internethealthlibrary.com/.

-WholeHealthMD.com. WholeHealthMD. com is sponsored by two healthcare companies: American WholeHealth, a provider of integrative medicine, and Rebus, a health and wellness publishing company. It endeavors to provide highquality, credible information on integrative medicine and general health for consumers. In the "Healing Center," users can search by ailment or condition and find causes, dietary advice, self-care techniques and lifestyle tips, conventional treatments, alternative therapies, and additional resources. The "Resource Library" provides explanations of alternative and complementary therapies and information on prescription and over-the-counter drugs. Also available are opportunities to e-mail questions to experts, links to health news, and a vitamin and supplement section. Access: http:// www.wholehealthmd.com/.

\section{General health sites with CAM information}

- InteliHealth. InteliHealth is a subsidiary of Aetna, Inc, a health benefit provider corporation. It has cooperated with Harvard Medical School and the University of Pennsyl- 
vania School of Dental Medicine to provide much of the content for the site. Information on complementary and alternative therapies, which conditions benefit from their use, and how the therapies work are available in the "Healthy Lifestyle" section. The site also provides tips on how to find a doctor/practitioner, an "ask the expert" column, and links to federal agencies and some private organizations. Access: http://www.intelihealth.com.

- WebMD Health. WebMD .com collects, organizes, and presents credible, reliable healthrelated information available over the Web. Searching and browsing its "Health" section returns basic background information about alternative and complementary medicine, different therapies, and information on their use and effectiveness. Users can also read news items, ask an expert a question, chat, or post to message boards. Most of the articles on the site indicate the author, the author's credentials, and the name of the reviewer. This site does accept advertising. Access; http://my.webmd.com/.

\section{Government-sponsored sites}

- CAM on PubMed. The National Library of Medicine and the National Center for Complementary and Alternative Medicine jointly created CAM on PubMed. CAM on PubMed searches a subset of PubMed, an online version of the MEDLINE database. Entering CAM on PubMed automatically limits search results to items that deal with complementary medicine. Access: http://www.nlm. nih.gov/nccam/camonpubmed.html.

- Complementary and Alternative Medicine for Serious Illness: Definitions. The Center for Disease Control at Columbia University is seeking information from individuals and health care providers about the use of CAM therapies in the treatment of serious illnesses.

This site is worth visiting for its definitions of CAM modalities and diseases even if you do not have an experience to share. Access: http:// www.camreports.hs.columbia.edu/diseases. html.

- healthfinder-Your Guide to Reliable Health Information. If you are a consumer looking for health information, consider starting your search at healthfinder. Developed by various U.S. government agencies to help consumers locate reliable health information, healthfinder lets users search a database of health information from government agencies, Web sites, online publications, and select nonprofit organizations. The "Health Library" portion

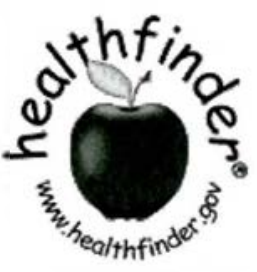
permits browsing by the general topic of "Alternative Medicine," with subtopics arranged in alphabetical order. Access: http://www. healthfinder.gov.

- MEDLINEplus: Alternative Medicine. A service of the National Library of Medicine, the MEDLINEplus section on Alternative Medicine contains links to the latest news about CAM from the media, articles and statements about CAM from the National Institutes of Health, information on related clinical trails, and recent research. This site also directs users to information on specific conditions and therapies published by government agencies and other organizations. Access. http://www.nlm.nih.gov/medlineplus/ alternativemedicine.html.

- National Center for Complementary and Alternative Medicine (NCCAM). NCCAM, which was established in 1998, is part of the U.S. National Institutes of Health. Its mission is to explore and investigate alternative and complementary therapies. Visitors to the site can find information addressing what CAM is and treatment information by CAM therapy or by ailment. Other areas of the site include recent and upcoming research, training opportunities, information on clinical trials, and news and events. CAM on PubMed, a subset of the public access MEDLINE database, and CHID (Combined

\section{Natignal Center for}

Complementary and Alternative Medicine

Health Information Database), a bibliographic database produced by health-related agencies of the U.S. government, are available from this site. Access: http://nccam.nih.gov/

- white House Commission on Complementary and Alternative Medicine Policy Final Report. In March 2000, President Bill Clinton established the White House Commission on Complementary and Alternative Medicine Policy. The commission was charged with investigating the state of research 
on CAM therapies and products, how CAM information and services are disseminated to the public, and how CAM practitioners are educated and licensed. In addition to the commission's "Final Report," visitors can read the transcripts of the commission's 14 meetings. Access: http://www.whccamp.hhs.gov/

\section{University-related sites}

- HealthWeb: Alternative Medicine. HealthWeb is a project of the National Network of Libraries of Medicine's Greater Midwest Region and the Committee on Institutional Cooperation, and is funded in part by the National Library of Medicine. The site was developed to organize credible, noncommercial, health-related Web sites. The section on alternative medicine, which is maintained by the University of Wisconsin's Health Sciences Libraries, leads to sites on various types of therapies, online publications, and therapies for specific health conditions. Access: http:// www.healthweb.org/.

- M. D. Anderson Cancer Center: Complementary/Integrative Medicine. Affiliated with the University of Texas, the M. D. Anderson Cancer Center is committed to providing current information on all possible cancer treatments to their patients and the public. This site provides evidence-based reviews of various complementary and integrative therapies and offers a glossary, a drug interaction advisory, and a list of selected links and additional resources. $A C$ cess: http://www mdanderson.org/departments/ cimer/

- Richard and Hinda Rosenthal Center for Complementary and Alternative Medicine. Created in 1993, the Rosenthal Center was one of the first centers at a major medical school developed to study alternative and complementary medicine and train medical professionals in their use. Affiliated with Columbia University, it also aims to become a recognized source of information on alternative and complementary medicine. Health consumers may be interested in their pages on specific therapies, their directory of databases, their information on training and education, and their list of general CAM resources. Access: http:// www.rosenthal.hs.columbia.edu.

\section{News and bulletins}

- Alternative Health News Online.

Frank Grazian, a communications emeritus professor at Rowan University and an award-winning journalist, created this site to educate the public about alternative therapies and preventive medicine. This site, which is updated daily, seeks to provide up-to-date, reliable information about alternative health choices. It consists of 12 major categories, such as "What's

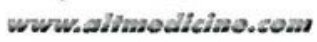

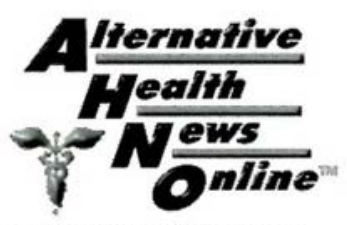
New," "Health News Bulletins," and "Alternative Medical Systems." "Health News Bulletin" gives brief synopses of news items and links to the news source reporting it. The site's search feature has links to five other health-related search engines, such as "PubMed," "Medscape," and "WebMedLit." Access: http://www altmedicine.com.

\section{Associations}

There are dozens of professional associations for practitioners of alternative and complementary therapies. Most target health care providers and offer information about training and education, news and events, and membership. Few offered significant information for the health care consumer.

- Acupuncture and Oriental Medicine Alliance. Access: http://www acupuncturealliance.org/.

- Alternative Medicine Foundation. The Alternative Medicine Foundation strives to provide health consumers and healthcare providers with reliable, evidence-based information on the integration of CAM therapies with traditional medicine. Three of its major projects are HerbMed (see description above), TibetMed (a Web site devoted to exploring Tibetan medicine), and a collection of resource guides. The resource guide topics include: "Choosing a Practitioner" and "General Information: An Alternative and Complementary Medicine Resource Guide." Additional resource guides cover 12 broad therapies. Each resource guide has an introduction to the therapy, including the training needed to practice it, recommended books and joumals, and links to professional (continued on page 589) 
sional Information Service): $\$ 3,000$ cash award for librarians who have implemented innovative approaches to information literacy at their respective institutions or in their communities.

- Community College Learning Resources Leadership/Library Achievement Awards (sponsored by EBSCO Subscription Services): $\$ 500$ cash for each of two awards recognizing outstanding achievement in library programs or leadership.

- Distinguished Education and Behavioral Sciences Librarian Award: Citation. Honors outstanding contributions to education and behavioral sciences librarianship through accomplishments and service to the profession.

- Women's Studies Section Awards for Achievement (sponsored by Greenwood Publishing Group, Inc. and Routledge): $\$ 1,000$ cash for each of two awards recognizing career or significant achievements in the area of women's studies librarianship.

\section{Research awards/grants}

- Doctoral Dissertation Fellowship (sponsored by Institute for Scientific Informalion): $\$ 1,500$ cash to assist doctoral students in the field with their dissertation research.

- Samuel Lazerow Fellowship (sponsored by Institute for-Scientific Information): $\$ 1,000$ cash for travel and writing in the fields of acquisition or technical services.

- Coutts Nijhoff West European Specialist Study Grant (sponsored by Coutts Nijboff International): Grant that supports re- ies, librarianship, or the book trade.

\section{Publication awards}

- Katherine Kyes Leab and Daniel J. Leab Exhibition Catalogue Awards (sponsored by Katherine Kyes Leab and Daniel J. Leab, American Book Prices Current): Recognizes outstanding catalogues published by American or Canadian institutions in conjunction with library exhibitions.

- K. G. Saur Award for Best Article in College \& Research Libraries (sponsored by $R, R$. Bowker/K. G. Saur): $\$ 500$ cash award for the most outstanding article published in CGRL during the preceding volume year.

- Instruction Section Publication of the Year Award. Recognizes an outstanding publication related to instruction in a library environment published in the last two years.

- The Oberly Award. This biennial award is given in odd-numbered years for the best English-language bibliography in the field of agriculture or a related science.

\section{Contact ACRL for details}

If you would like more information about the ACRL 2003 Awards Program, visit our Web page at http://www.ala.org/acrl.award2.html or contact ACRL Program Coordinator Stephanie Sherrod at (800) 545-2433 ext. 2515, e-mail: ssherrod@ala.org.

We welcome your nominations and look forward to celebrating achievements in academic librarianship in 2003.

- American Chiropractic Association. The section for consumers and the media has an overview of chiropractic medicine, health tips, news, and an FAQ. Access: http:// www.amerchiro.org.

- American Holistic Medical Association. Access: http://www.holisticmedicine. org/

- Association for Integrative Medicine. $A C$ cess: http://www integrativemedicine.org/

- National Center for Homeopathy. This association strives to provide basic information on homeopathy for the public. Sections include homeopathy in the news, research, clinical studies, an introduction to homeopathy, and

(continued on page 599) 
Perhaps the most poignant are scenes from the marketplaces, streets, bars, and music halls that are the heart of the city. $\$ 29.95$. Chicago Review. ISBN 1-55652-439-0.

Jack the Ripper: An Encyclopedia, by John J. Eddleston (304 pages, October 2001), rates as one of the easier-to-use Ripper sourcebooks. British scholar Eddleston organizes the entries into alphabetical sections on the victims, the witnesses, the police investigators, others who played a part, a chronology, descriptions of Jack, letters he supposedly wrote, myths and errors, locations, the suspects (each assigned a number referring to the likelihood of his being the Ripper), qualitative reviews of other Ripper books (generously noting any errors of fact the author makes), other resources, and a summary in which the author lets loose with his own assessment of the case. Well-researched, with minimal distractions and subjectivity. $\$ 75.00$. ABC-Clio. ISBN 1-57607$414-5$.

\section{London Booksellers and American Cus-} tomers, by James Raven (522 pages, May 2002), explores in great detail the book pur-

("Complementary and alternative medicine" continued from page 589)

links to find a homeopathic practitioner. $A C$ cess: http:/ www homeopathic. org.

- Research Council for Complementary Medicine. Access: http://www rccm. org.uk/index.htm.

\section{Consumer health protection sites}

- National Council Against Health Fraud (NCAHF). NCAHF, a private, nonprofit organization, tackles health fraud as a public health concern. Their Web site features occasional papers, position papers and task force reports, testimony given before Congress, and consumer information statements on specific treatments and therapies. Most of the articles on the site are researched and written by physicians, nurses, and other health care professionals. Also on the site is access to a speakers bureau, an electronic newsletter, links to similar sites, and breaking news. Access: http:// www.ncahf.org/.

- Quackwatch: Your Guide to Health Fraud, Quackery, and Intelligent Deci- chases and correspondence of the Charleston (S.C.) Library Society from 1748 to 1811 . The archives of the society provide a unique glimpse into both the transatlantic book trade and the role of library societies in the diffusion of cultural and intellectual pursuits throughout the South during the latter half of the 18 th century. Particularly useful for collections in the history of the book trade. $\$ 59.95$. University of South Carolina. ISBN 1-57003-406-0.

\section{The Oxford Companion to American}

Law, edited by Kermit L. Hall ( 912 pages, July 2002), explains in clear language the concepts, terms, practices, agencies, individuals, crimes, and proceedings that make up American jurisprudence. Nearly 500 essays, written by some 300 contributors, provide authoritative commentary directed at general readers, students, journalists, and nonlegal scholars. The topics are extremely diverse, ranging from the Salem Witchcraft Trials and Busb v. Gore (2000) to consumer law, torts, governance, taxation, evidence, and criminal procedure. An excellent introduction that serves as a one-volume first step to legal research. $\$ 65.00$. Oxford University. ISBN 0-19-508878-6.

sions. Quackwatch, a nonprofit corporation created to battle health fraud and promote consumer health awareness, was founded by Stephen Barrett, M.D., in 1969. The Web site consists of links to articles and information on suspicious treatments, diagnoses, and therapies as well as individuals, companies, and publishers who support them. The articles are written by medical, scientific, or legal specialists, and many include lists of references. Another section of Quackwatch includes information about questionable advertisements and non-recommended sources of health advice. The site also includes information on where to report health fraud and how to be an intelligent health consumer. Access: http://www.quackwatch.com.

\section{Notes}

1. Helen Lippman, "Can complementary and conventional medicine learn to get along?" Business \& Health (2001) 9: 15-19.

2. Ibid.

3. National Center for Complementary and Alternative Medicine, "What is Complementary and Alternative Medicine?" http://nccam. nih.gov/health/whatiscam/. 